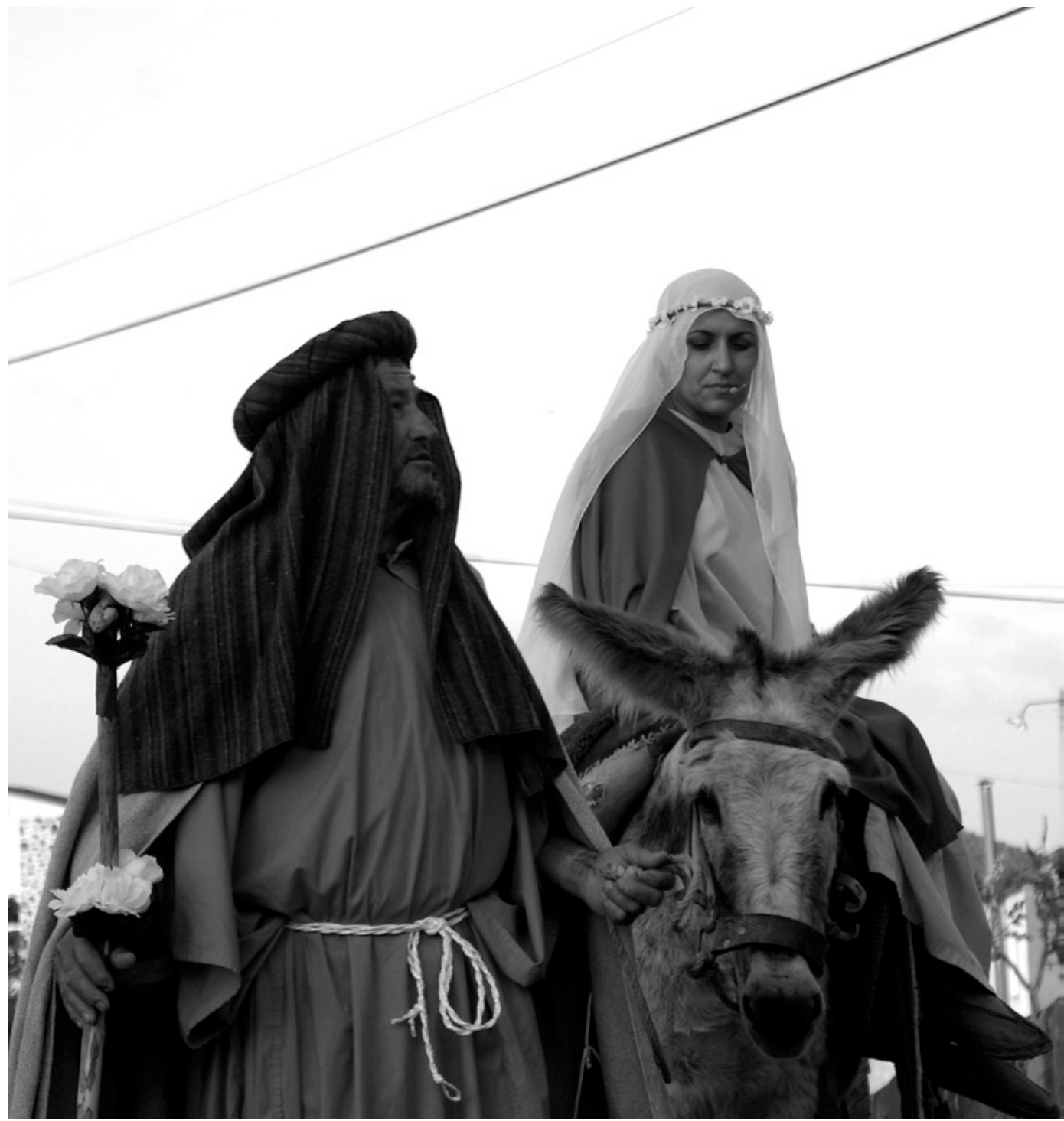

Visitação de Santa Isabel Urrós, 2011 (José Maria Meleiro (S. José)

e Maria de Nazaré (Susana Monteiro)), fot. Secundino Miranda.

\title{
Um grande Auto numa pequena aldeia transmontana
}

\section{David Luís Casimiro}

Remexendo nas arcas da memória

Sob orientação do Professor João David Pinto Correia, em Literatura Oral e Tradicional, procedemos à recolha de tradições orais na aldeia transmontana de Urrós, concelho de Mogadouro, onde nascemos há trinta e cinco anos. Na nossa memória, continua presente a imagem dos que, naquela altura, conseguiram impressionar-nos com as suas histórias, as lengalengas, as rezas, os anfiguris, e até fragmentos daquilo que viriamos a descobrir tratar-se de excertos do Auto da criação do mundo ou Princípio do mundo, recordações avulsas de uma representação sacra, que uma triade de regrantes locais havia levado à cena nas Eiras de Urrós, em, pelo menos, três ocasiões, conforme recordavam os nossos informantes: 1924, 1935 e 1949.
Chegámos à descoberta de um Casco, de Salustiano Augusto Ovelheiro, o qual fundamenta as referidas representações. Actualmente na posse dos seus descendentes, o manuscrito apresenta marcas do tempo e do mau acondicionamento. Urgia, por isso, recuperá-lo, uma vez que apresenta lacunas textuais, umas delidas pela humidade, outras por omissão do escriba. Confrontando o Casco com a memória daqueles que participaram na representação do Auto da criação do mundo, intentámos reconstituir uma versão próxima da dirigida por Salustiano Augusto Ovelheiro, em 1949. Assim surgiu a dissertação de Mestrado, que apresentámos à Faculdade de Letras de Lisboa em 2008, tendo continuidade na tese de Doutoramento, elaborando uma versão crítica dos dramas populares transmontanos comummente designados por Auto da criação do mundo, ou também por Ramo.
David Luís Casimiro integra como

investigador o Centro de Tradições Populares Portuguesas da Faculdade de Letras da Universidade de Lisboa, é Licenciado em Linguas e Literaturas Modernas - Estudos Portugueses, Mestre em Literatura Oral e Tradicional e prepara o seu doutoramento na mesma área. 
Cortejo de abertura da representação do Auto,

em Maio de 1949 António Maria Mourinho.

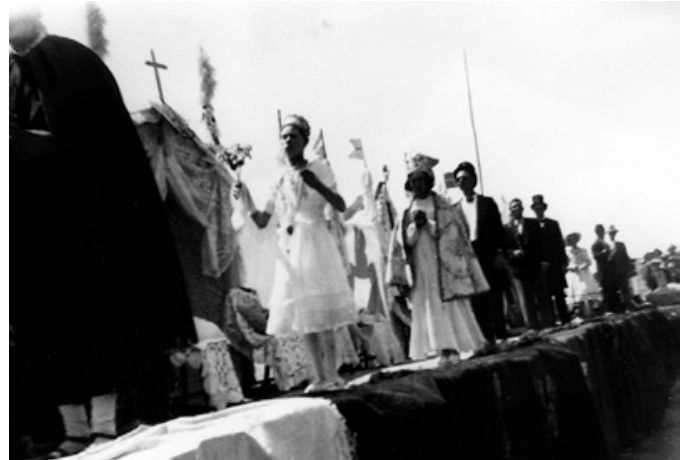

Chegada dos Reis Magos, Urrós, 2011 (Nelson Parra (Baltazar) Vitor Ferreira (Gaspar) Hélder Casado (Belchior) fot. Secundino Mirand

Após a fixação do texto, pareceu-nos que o ciclo da obra se completaria com a sua representação, alguns revisitando a memória desses tempos, e outros descobrindo uma tradição local. Foi crucial a participação de Fernando Augusto Alves, que, em 1949, com apenas onze anos de idade, representou o Anjo. Graças a ele recuperámos não só excertos omissos, como, passados 62 anos, podemos reviver a anterior experiência, com ele subindo ao "tabuado" de Urrós, para desempenhar os papéis de Adão, e de Caim no dia 19 de Agosto de 2011, pelas cinco horas da tarde.

A recriação colocou problemas: os tempos cambiaram drasticamente, a aldeia foi-se despovoando inevitavelmente. Havia que procurar soluções para fazer participar o povo de Urrós do nosso projecto de reconstituição teatral. Todos contribuiram segundo as suas possibilidades, mesmo ausentes e apenas se reunindo em breves momentos. Após cerca de um ano de ensaios esporádicos, 43 actores amadores locais, homens e mulheres chegados de vários quadrantes, no remanso das suas férias, ou aproveitando o descanso de fim-de-semana, refizeram, na integra, a representação do Auto da criação. De Salustiano Augusto Ovelheiro, ficou o registo cenográfico utilizado: um longo palco, feito de tábuas cedidas pela população, cujos nomes se inscreviam, a tinta, no seu verso, para que pudessem ser devolvidas, terminada a função. Sobre esse tabuado, construiu-se uma sequência de casas, em ripado de madeira cobertas por colchas, também emprestadas, cujo todo evoca as mansões medievais do palco de Vincennes, que as histórias de teatro reproduzem. Em 1949, esse dispositivo no local das Eiras de Urrós, media cem metros de comprido. Não permitindo a urbanística actual tamanha envergadura foram as casas reduzidas a 17, e o tabuado substituido por 22 atrelados; marcas de tempos diferentes, porém, o mesmo espírito empreendedor. Desde o início de Agosto, entre ensaios e elaboração dos preparativos, os actores amadores de Urrós dedicaram o seu tempo ao apuramento das suas interpretações, sob nossa orientação, e o saber dos mais velhos, das memórias despertadas.

0 acontecimento ganhou contornos institucionais, contando com o apoio da Junta de Freguesia local, da Câmara Municipal de Mogadouro, que promoveram o convite às populações de outras localidades, com idêntica tradição espectacular, que se fizeram representar, e acolheram a participação da Faculdade de Letras da Universidade de Lisboa, através do Centro de Tradições Populares Portuguesas Manuel Viegas Guerreiro (CTPPFLUL) e do Centro de Estudos de Teatro (CET-FLUL), num Colóquio sobre teatro popular e a memória das representações do Ramo. Na véspera da representação, o povo de Urrós assistiu a uma amena tertúlia com

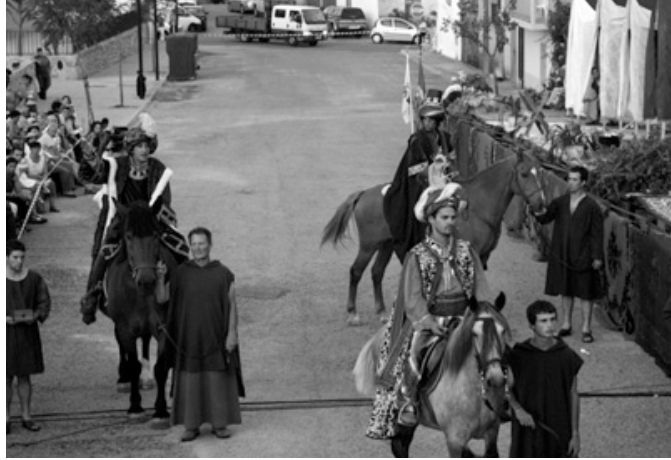

investigadores destes Centros de estudo, cujas comunicações darão lugar, futuramente, a um livro patrocinado pela autarquia de Mogadouro. Participaram do Colóquio, presidido pelo autarca de Mogadouro, António Machado, e pela Vereadora da Cultura, Teresa Sanchez, e por nós moderado, os professores Manuel Carlos Patrício (CTPP), Francisco Ferreira (CTPP), Amanda Guapo (GEFAC), Amadeu Ferreira (Associação de Llengua Mirandesa) e Guilherme Filipe (CET).

O Auto da criação do mundo ou Princípio do mundo Apesar da designação, não se trata de um auto no sentido exacto da palavra, mas de um conjunto de dramatículos autónomos, reflectindo passagens específicas da Bíblia, que o espírito criativo do regrante entreteceu em forma espectacular, numa colagem textual, um pastiche, seguindo uma lógica doutrinal paralelística entre o Velho e o Novo Testamento, como se de uma via sacra do Homem se tratasse. Deste modo, assumem-se de forma natural duas jornadas, interligadas por uma espécie de entremez popular, comédia de amores trocados, entre pastores e pastoras. Aliás, parece-nos ser o Amor o tema primordial da obra representada. Se a primeira jornada reflecte os problemas que ao Homem advêm quando perde o amor de Deus e o Paraiso, a segunda jornada proclama a redenção definitiva pelo amor em Cristo Menino, no Ciclo da Natividade, e o vislumbre da reconquista do Paraíso, que a Paixão de Cristo, no Ciclo da Quaresma, realizará. Pelo meio, fica a vivência humana, sem consciência que a transcenda, ao sabor de tentações constantes, até que a boa nova lhes faça ver a luz da salvação.

Abre o Auto com o Anjo, no Éden, que proclama o poder divino sobre toda a criação - versículos iniciais do Livro do Génesis -, para dar lugar ao Acto de Adão e Eva, página adâmica tradicional, relatando a tentação demoníaca e a expulsão dos progenitores da geração humana, condenados à intranquilidade das labutas terrenas. $\mathrm{Na}$ continuação, o Acto de Abel, Seth e Caim exibe a expiação constante do ser humano na reconquista do amor divino; exortam-se os caminhos da virtude abnegada, e reprovase a soberba, a raiva e a inveja, vícios que levam Caim a matar Abel, e o condenam à errância, em decadência gradual, e, tomado por animal selvagem, ser morto pelo caçador Lameque. Arrastam, os Diabos a Caim, por entre galhofas, ao Inferno, e assim "fenece" o tempo do Antigo Testamento.

Aliviando o sofrimento do auditório, após tão trágico desfecho, introduziu o regrante um momento de riso, sem, contudo, perder a seriedade na abordagem do tema e no respeito pelo decoro. No Acto da inveja e Diabo, Silvestre, 


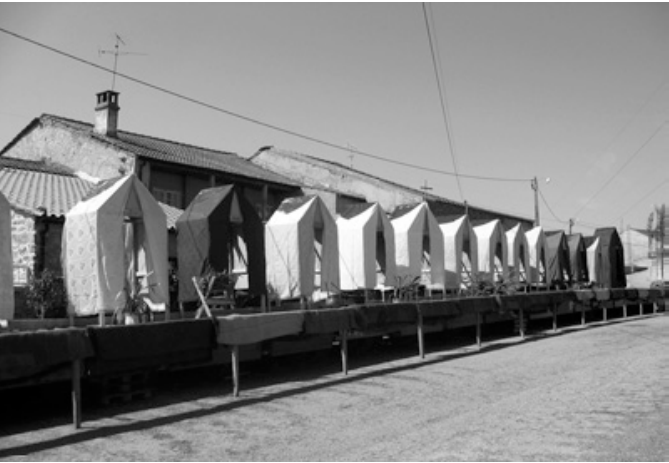

Tablado da representação do Auto em Agosto de 2011, fot. Secundino Miranda.

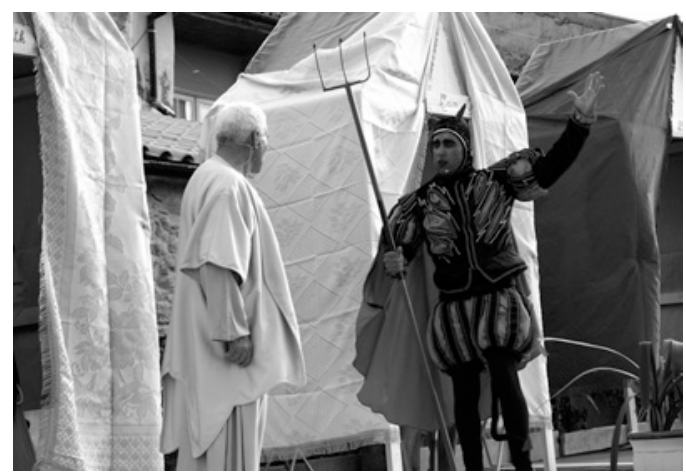

Vulcano, Narciso, Beliza, Júlia e Rebeca, o enredo deambula por ingénuos amores pastoris, com graciosos criados levando e trazendo recados, enquanto a Inveja e o Diabo fomentam a zizania. E todos se perderiam, não fora a aparição do Anjo ex machina, o General S. Miguel, que, em boa hora, desterra a maldade, e anuncia o nascimento do menino. E com esta acção se introduz o tema do Novo Testamento.

A segunda jornada narra o novo ciclo da Humanidade, estabelecendo, contudo, uma ligação racional com a primeira. Cristo será o Adão de uma nova era, de um tempo de remissão prometido no Antigo Testamento, fruto de intervenção divina através de uma jovem judia imaculada. Seguindo de perto o Evangelho de S. Lucas, apresentamse os primeiros passos dos mistérios da Virgem Maria: a educação de Maria no Templo, e o seu desejo de fazer voto de castidade ao Altíssimo; a primeira revelação a Simeão sobre as intenções supremas do casamento de Maria com José; a escolha deste por milagre divino, fazendo florescer açucenas no seu bordão; a visita da Virgem a sua prima Isabel e a profetização do Redentor; o pranto de José, angustiado pela incompreensão da transcendência revelada, dividido entre o dever de confiar e a dúvida da fidelidade da esposa, entre a acusação pública de adultério e a aceitação de uma paternidade que o ofende. Toda a narrativa nos conduz até Belém, ao Presépio, ao nascimento, à primeira epifania aos pastores, todos eles bons transmontanos, diga-se, carregando no seu "bornal" o produto do seu sustento - "fogaça, trigo, figo e lã" -, conscientes da simplicidade da dádiva, feita apenas pelo amor do próximo.

Aproxima-se o desfecho com a entrada dos Reis Magos, precedidos pela estrela. Momento que se pretende aparatoso, em contraste com a simplicidade anterior, pede o regrante que estas potestades cheguem a cavalo, anunciadas por trombetas. 0 tema amplia-se à esfera dos poderosos, com Herodes, tetrarca da Galileia, entrando sombrio, temendo que o anunciado Rei dos Judeus retire

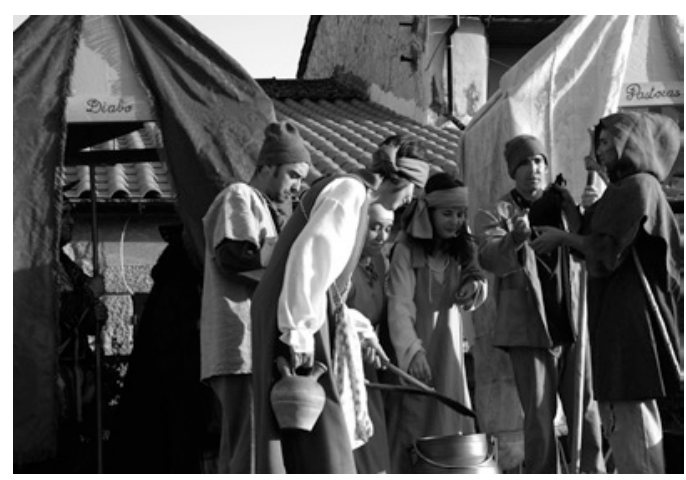

Acto de Abel, Seth e Caim Urrós, 2011 (Fernando Alves (Caim) e Carlos Preto Alves (Diabo)), fot. Secundino Miranda.

o seu poder real. Tal como nos passos bíblicos, o Anjo fará as revelações necessárias para que os Magos possam adorar o Salvador e desviar-se da iniquidade de Herodes. Indo todos adorar o Menino, se conclui a escrita do Auto da criação do mundo ou Princípio do mundo, na aldeia de Urrós.

\section{Auto segundo Salustiano Augusto Ovelheiro ou} o Modo dos Regrantes

Para José Oliveira Barata os regrantes, ou regentes, são poetas populares, pessoas sabedoras e receptoras da tradição local, que detendo o Casco, em cada ano, o utilizam para a representação de Colóquios, Estrelóquios, Comédias ou Autos. Quem privou com Salustiano Ovelheiro descreve-o como uma pessoa que "conhecia muitas coisas, um entendido", não só organizando o evento, como metendo mão na escrita do texto. Não seria o seu autor - a semelhança textual é notória entre as aldeias

transmontanas que representam as várias versões do auto -, mas um arremedador, crente talvez de Ihe dar melhor feitura, ou para suprir a novidade que as plateias anseiam sempre, mesmo que seja matéria religiosa tradicional. Era sua competência seleccionar os intérpretes, dirigir os ensaios e reunir os materiais necessários à cenografia, para que a função fosse tão digna quanto a elevação do tema. Contava com o apoio de dois homens; enquanto participavam no ofício dominical, postavam-se ao fundo da igreja, e observavam os devotos, alheios ao casting que Ihes estavam fazendo. Missa terminada, no adro da igreja, procedia-se ao convite de quem reunia as qualidades próprias à interpretação dos papéis. Constituído o elenco, passava-se aos ensaios, principiando por altura de Junho, durante meio ano, primeiro ao ar livre, mas logo após Setembro, em crescendo as noites e os frios enregelando, deslocava-se o povo para o curral, cedido por um proprietário local abastado, espaço amplo que permitia construir-se um pequeno palco, para marcação dos episódios.
Comédia dos Pastores, Urrós, 2011

(Luis Granado (Narciso) Luis Castro (Vulcano), João Barros (Silvestre), Natália Lopes (Beliza),

Celina Lopes (Júlia) e Maria Margarido (Rebeca)),

fot. Secundino Miranda. 


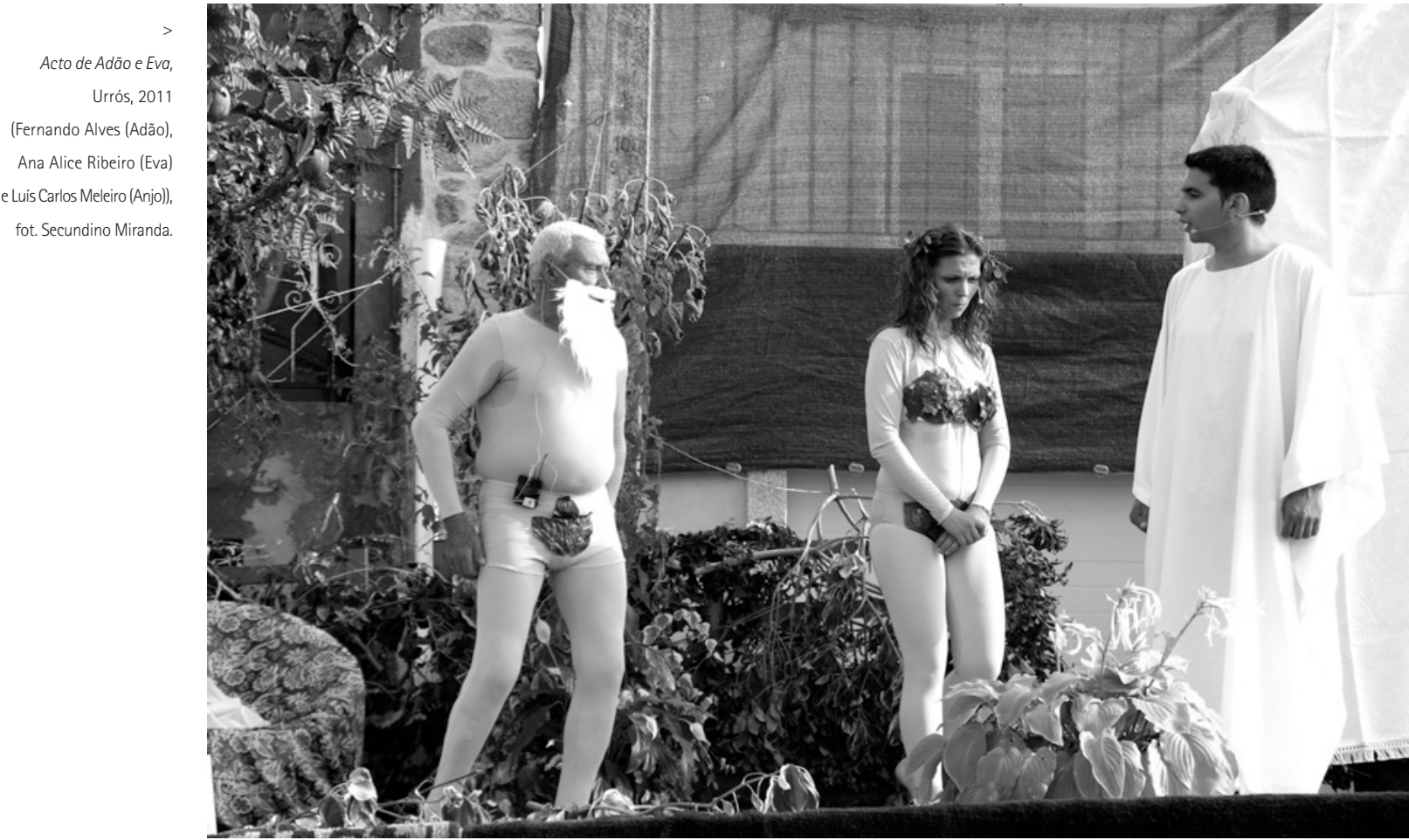

Salustiano Ovelheiro trabalhava afincadamente a elocução especifica de cada papel, ensinava o tom laudatório adequado, que a gestualidade ampliada ilustrava, criava signos teatrais. Uma prosódia semelhante à tradicional declamação amadora, mas que, por outro lado, se coadunava com o espaço da eira da aldeia, e da sua sonoridade ambiente, para disso tirar partido no momento da representação.

A concepção plástica reproduzia a imagética interior da igreja, os modelos da santaria e dos retábulos. 0 guardaroupa era executado segundo padrões tipificados pelos habitantes da aldeia. Confidenciou Fernando Alves que, para representar o papel de Anjo, pediu emprestado o "fato de comunhão de uma filha da terra com posses". Nos papéis de Nossa Senhora, ou do velho Simeão, usavamse paramentos existentes na Igreja, sem que nisso houvesse sinal de heresia. Os adereços provinham do que se encontrava no lar de cada um, consoante a exigência da narrativa. Minha avó emprestou uma roca para que Eva pudesse fiar, e Abel teve de ir à feira de Mogadouro mercar uma enxada, se quis estar a preceito. Todo o povo participava deste acontecimento múltiplo e complexo, que se repetiu até à década de 1950.

Revisitação da memória dos nossos antepassados Após dois anos de investigação, sofrendo os rigorosos Invernos transmontanos e as estradas de difícil acesso, ouvindo a enorme saudade daqueles que recordavam o Auto da criação do mundo, propusemo-nos recriar a representação ocorrida 1949. Contámos com o apoio incondicional de Fernando Alves, que passou o testemunho ao novo Anjo e assumiu a interpretação dos papéis de Adão e de Caim. Durante um ano, as 43 pessoas escolhidas empenharam-se em levar a bom termo a complicada revisitação da memória dos nossos antepassados. No inicio, não se deram conta da responsabilidade para a qual tinham sido chamados. Os mais "entendidos" recordaram a importância de "ser escolhido" para um papel, e os mais novos, escutando, com o avançar dos ensaios, ganharam consciência do ser-actor: decorar os versos, para se imbuir das características próprias da personagem; a representação não pode sofrer desleixo. Os ditames experientes dos mais velhos foram regularizando a falta de jeito dos principiantes.

Ana Alice Domingues, bisneta de Salustiano Ovelheiro, no papel de Eva, e o Fernando Marques, neto de António José Guerra, no papel de Lameque, pela sua ligação familiar à triade de Regrantes, sentiram uma responsabilidade geracional acrescida. Indiscutivelmente, o sucesso da representação deveu-se à determinação dos participantes. Susana Ferreira (Maria de Nazaré), que reside em Barcelona e todos os que vivem longe da aldeia natal, trocaram a tranquilidade das férias para, nos derradeiros ensaios, cumprirem o desafio abraçado. Exemplos que incentivaram a gente da aldeia, e, por isso, todos colheram o aplauso da grande plateia presente.

A vida aldeã trasmontana não se compara com os modos antigos. A revisitação do Auto da criação do mundo - inicialmente uma investigação académica para fixação de uma tradição oral -, constituiu-se em participação colectiva, em motivo de orgulho cultural da pequena localidade de Urrós, cujas gentes sentiram prazer em reviver a sua tradição de Natal Transmontano, mesmo que, por comodidade actual, tenha ocorrido em Agosto, mês do emigrante. Os meios de comunicação divulgaram o acontecimento, registou-se a representação para memória futura, salvaguardou-se a tradição na modernidade dos bytes de um pequeno disco. A lembrança da alegria e a saudade dos tempos de infância dos mais velhos, e a transmissão das experiências para os mais novos, ficaram para sempre gravados no Museu da aldeia inaugurado na ocasião, e onde uma placa evocativa do acontecimento, ofertada pelo autarca de Mogadouro, perpetua o nome de quem, um dia, cumpriu o sonho de viver o Auto da criação do mundo, em Urrós. 